\title{
Питание сига Coregonus Lavaretus, европейской ряпушки C. Albula и европейской корюшки Osmerus Eperlanus в оз. Имандра
}

\author{
Зубова Е.М., Кашулин Н.А. \\ Институт проблем промышленной экологии Севера КНЦ РАН, Anamumbl, zubova@inep.ksc.ru
}

Аннотация. Исследовано питание наиболее многочисленных видов рыб крупнейшего субарктического оз. Имандра - сига Coregonus lavaretus, европейской ряпушки C. albula и европейской корюшки Osmerus eperlanus. Было выявлено, что по типу питания европейская корюшка может быть классифицирована в Имандре, как типичный хищник-ихтиофаг, питающийся в основном ряпушкой и девятииглой корюшкой, в то время как малотычинковый сиг и европейская ряпушка - как всеядные хищники, отдающие предпочтение макрозообентосу.

Ключевые слова: оз. Имандра, доминантный и субдоминантный вид, питание, сиг Coregonus lavaretus, ряпушка C. albula, корюшка Osmerus eperlanus

\section{The feeding of whitefish Coregonus Lavaretus, vendace C. Albula and smelt Osmerus Eperlanus in Imandra lake}

\author{
Zubova E.M., Kashulin N.A. \\ Institute of the North Industrial Ecology Problems KSC RAS, Apatity, zubova@inep.ksc.ru
}

\begin{abstract}
The feeding of the most numerous species of fish from the largest subarctic Imandra Lake - whitefish Coregonus lavaretus, vendace C. albula and smelt Osmerus eperlanus was investigated. It was found that by feeding type, smelt can be classified as a piscivorous predator, eating mainly vendace and nine-spined stickleback, while sparsely rakered whitefish and vendace as omnivorous predators oreferring benthic macroinvertebrates.

Key words: Imandra Lake, dominant and subdominant species, feeding, whitefish Coregonus lavaretus, vendace C. albula, smelt Osmerus eperlanus.
\end{abstract}

\section{Введение}

Оз. Имандра - один из крупнейших антропогенно-трансформированных заполярных во-

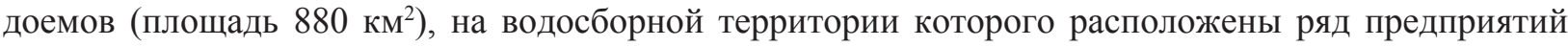
горно-перерабатывающей и металлургической промышленности, энергетики, транспорта и их инфраструктуры (Kashulin et al., 2017 и др.). Наряду с продолжающимися изменениями гидрологического и гидрохимического режимов, антропогенное эвтрофирование водоема становится доминирующим фактором, снижаюшим его ресурсный потенциал (Денисов, Кашулин, 2016). Изменения затронули и рыбную часть населения водоема, значительно ускорив сукцессионный переход от сигово-лососевого к корющково-окуневому водоему (Решетникова и др., 2011). Был показан переход сига Coregonus lavaretus из статуса доминантых видов в субдоминантный с увеличением в уловах количества европейской корюшки Osmerus eperlanus. В настоящее время (2011-2016 гг.) эта тенденция сохраняется, при этом к числу доминантных и субдоминантных видов озера добавились окунь Perca fluviatilis и ерш Gymnocephalus cernuиs. Такой переход является ответной реакцией сообщества на изменение трофического статуса водоема, вызвавшего количественные и качественные изменения структурно-функциональной организации экосистемы, в том числе радикальные перестройки пищевых сетей, позволяющие доминировать короткоцикловым эврифагам.

Целью настоящей работы было сравнительное исследование современного питания наиболее многочисленных видов рыб оз. Имандра - сига Coregonus lavaretus, европейской ряпушки C. albula и европейской корюшки Osmerus eperlanus.

\section{материал и методы}

Для качественного и количественного анализа питания сига, корюшки и ряпушки в оз. Имандра в летне-осенний период было просмотрено содержание желудков 304 особей, согласно известным руководствам (Методическое..., 1974). Для оценки питания исследуемых видов рыб из различ- 
ных районов озера, были выделены 4 размерные группировки: для сига - 100-199 мм, 200-299 мм, 300-399 мм и 400-499 мм, для ряпушки и корюшки - 0-100, 101-150, 151-200 и 201-250 мм.

\section{Результаты}

Сиг. Учитывая малочисленность среднетычинкового сига в оз. Имандра (Зубова и др, 2018), в работе приводятся данные только по малотычинковому сигу (далее мт.с.) разных плесов озера.

Анализ спектра питания мт.с. оз. Имандра показал, что он включает относительно широкий набор объектов: 27 родов, 1 группу, 3 отряда, 1 подкласс беспозвоночных животных, а также рыбу и ее икру (табл. 1). Растительные объекты в составе пищи были встречены только в желудке 1 крупной особи мт.с. $(F L=284$ мм) и, скорее всего, являются случайной пищей. Главной пищей сигов первой размерной группы (100-200 мм) плесов Йокостровская Имандра (далее ЙИ) и Бабинская Имандра (БаИ) служили, как представители донной фауны (двустворчатые моллюски и хирономиды), так и пелагической (крупные ракообразные) (табл. 1). С увеличением линейных характеристик мт.с. (от 200 до 400 мм) во всех плесах озера главное место в питании начинают занимать такие донные организмы, как моллюски (двустворчатые и брюхоногие) и ручейники. У мт.с. размером $>260$ мм в желудках появляется рыба. В конце августа-сентябре в желудках сига появляется икра осенненерестующих рыб, возможно ряпушки или самого сига. Несмотря на большую частоту встречаемости, а в ряде случаев и биомассу коловраток в составе зоопланктона Имандры (Зубова и др., 2018), они не встречались в желудках рыб ни одной возрастной группировки сига, что, возможно, связано с очень мелкими размерами этих организмов (размеры меньше, нежели расстояние между тычинками на жаберных дугах сигов) или же быстрой их перевариваемостью и невозможностью дальнейшего определения в составе пищевого комка. Несмотря на высокую биомассу олигохет в профундальном бентосе Большой Имандры (БоИ) (Зубова и др., 2018), они редко встречаются в желудках рыб этого плеса. С увеличением линейных характеристик сига оз. Имандра наблюдается тенденция роста относительного веса пищи в желудках рыб, средние размеры объектов питания увеличиваются (табл. 1).

Ряпушка. Спектр питания европейской ряпушки оз. Имандра также включал широкий набор объектов: 19 родов, 4 семейства, 3 отряда, 1 подкласс и 1 тип беспозвоночных животных (табл. 2). В желудках особей ряпушки первой размерной группы (0-100 мм) плесов ЙИ и БаИ наиболее часто встречались зоопланктонные организмы (мелкие ветвистоусые ракообразные) и такие бентосные организмы, как куколки хирономид. С увеличением размеров от 101 до 150 мм в рационе ряпушки трех плесов особых изменений в питании не наблюдалось. У ряпушек длиной от 151 до 200 мм в рационе начинают резко преобладать бентосные организмы - куколки хирономид и имаго ручейников, в небольшом количестве встречаются поденки, веснянки, двустворчатые моллюски и пиявки. В желудках крупных ряпушек (201-205 мм) ЙИ встречались, как зоопланктонные (крупные ветвистоусые ракообразные), так и бентосные организмы (брюхоногие моллюски). С увеличением линейных характеристик ряпушки оз. Имандра происходит уменьшение относительного веса пищи в желудках рыб, средние размеры объектов питания увеличиваются (табл. 2).

Корюшка. Были рассмотрены желудки корюшек только из ЙИ и БаИ. У корюшки из плеса ЙИ длиной 0-100 мм (1 экз.) присутствовали зоопланктонные организмы рода Bosmina sp. (до одной тыс. экз.). У особей длиной 100-150 мм (4 экз.) в желудках присутствовала только рыба, в частности ряпушка. У корюшки из БаИ сходной размерной группировки (1 экз.) в желудке присутствовали бентосные организмы: куколки ручейников семейства Leptoceridae и поденки рода Ephemera. У рыб большей длины (от 150 до 250 мм) (30 экз.) в обоих плесах содержимое желудков включало в основном только рыбу: ряпушку и девятииглую колюшку Pungitius pungitius. С линейным ростом корюшки средние размеры объектов питания увеличиваются (от 0.5 до 68.3 мм), относительный вес пищи в желудках растет у рыб длиной до 200 мм (от 17.9 до $185.1 \%$ в ЙИ и от 47 до $1006.8 \%$ в БаИ), затем - уменьшается. 


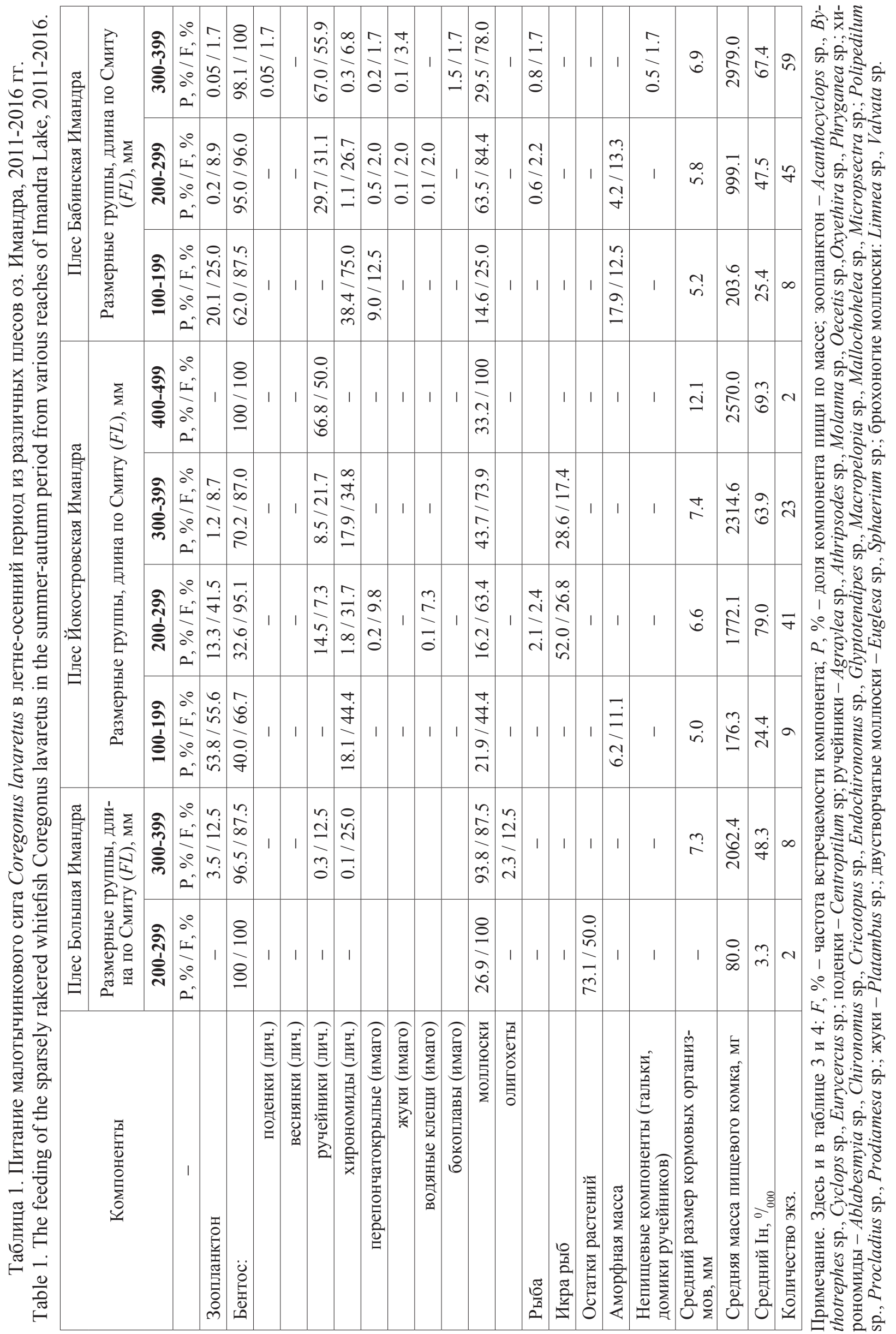




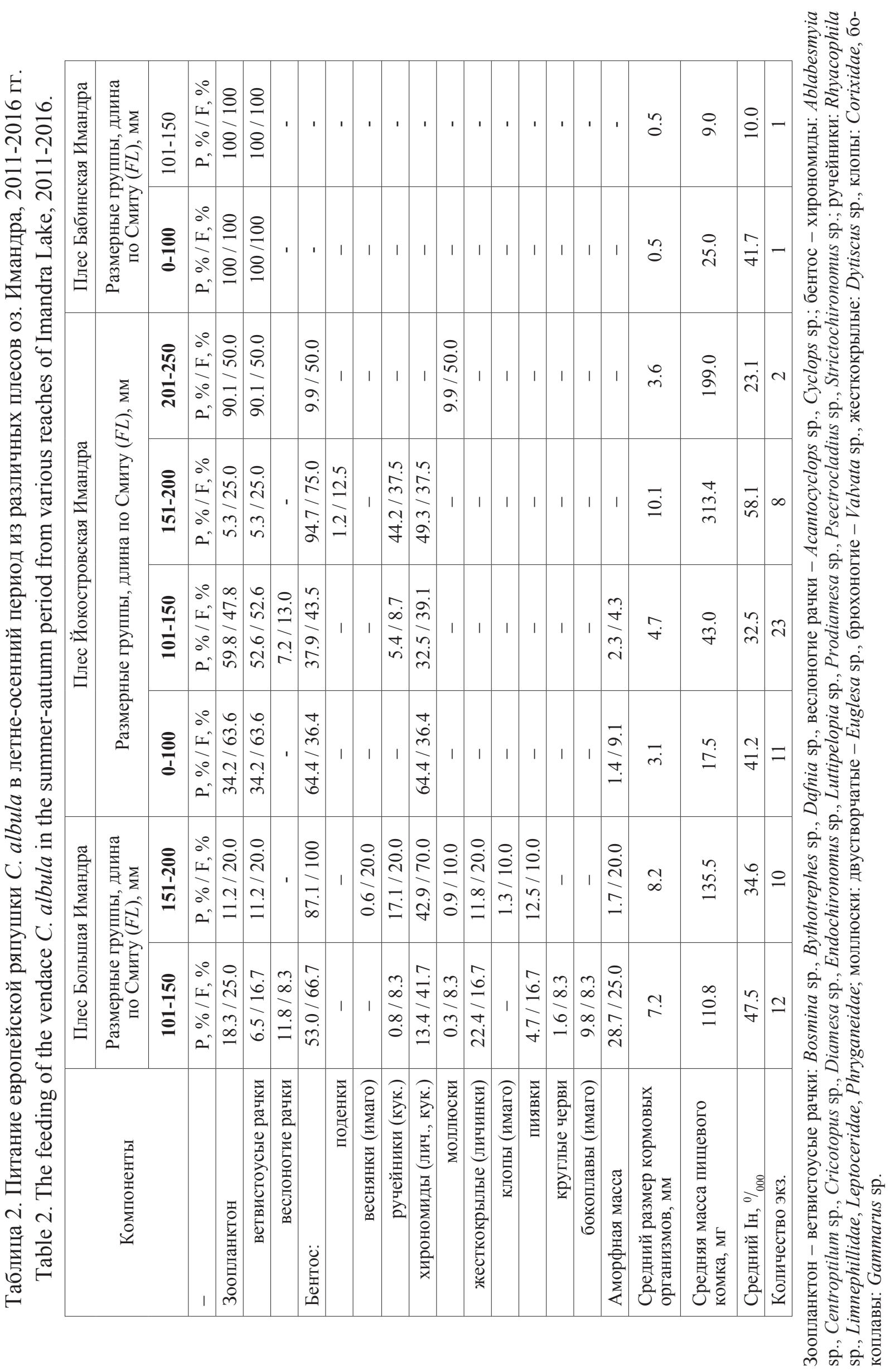




\section{Обсуждение}

Таким образом, исследованиепитания ядра рыбной части сообщества оз. Имандра показало, что европейская корюшка здесь может быть классифицирована, как типичный хищник - ихтиофаг, питающийся в основном ряпушкой и девятииглой колюшкой, в то время как мт.с. сиг и европейская ряпушка - как всеядные хищники, отдающие предпочтение макрозообентосу. Массовая доля зоопланктонных организмов в питании сига и ряпушки уменьшается с увеличением линейных характеристик рыб. Содержимое желудков сига длиной 200 и более мм в среднем на 95 \% состоит из представителей литорального макрозообентоса - брюхоногих моллюсков и личинок ручейников, у ряпушки длиной более 150 мм в среднем на $75 \%$ - из представителей литорального и профундального макрозообентоса: личинок-куколок хирономид и куколок ручейников. По литературным данным представленные особенности питания характерны только для мт.с. (Решетников, 1980). Хищный образ жизни у корюшки наблюдается только у крупных особей (>250 мм), в основном ей характерен бентосный тип питания. Ряпушка является типичным планктонофагом в бореальных озерах (Northcote, Hammar, 2006), в олиготрофных субарктических озерах с низкими количественными показателями зоопланктона ряпушка переходит на бентосное питание (Berezina et al., 2018). Оз. Имандра является субарктическим водоемом, где олиготрофный статус вод по количественным показателям зоопланктона характерен только для плеса БаИ, тогда, как для вод плесов ЙИ и БоИ этот статус меняется от а-мезотрофного до $\beta$-эвтрофного (Зубова и др., 2018). Несмотря на высокую численность и биомассу зоопланктона в этих плесах, ряпушка здесь предпочитает питаться макрозообентосными организмами. Возможно, этот выбор можно объяснить тем, в составе зоопланктона оз. Имандра по численности и по биомассе преобладают коловратки, а не ракообразные (Зубова и др.. 2018), которые являются основными объектами питания ряпушки в бореальных водоемах (Northcote, Hammar, 2006). Таким образом, ряпушке в оз. Имандра энергетически выгоднее питаться бентосными организмами, нежели зоопланктонными. Ряпушка в оз. Имандра вынуждена питаться бентосными организмами, конкурируя с сигами. Эвритопная корюшка демонстрирует эврифагность, позволяющую при различных экологических условиях и в различные периоды жизни переходить с одного вида пищи на другой, включая хищничество, что обеспечивает ей способность поддерживать высокую численность и успешно конкурировать с другими видами, фактически не имея врагов.

Работа выполнена в рамках темы НИР №0226-2019-0045 и частично подержана из средств гранта РФФИ 18-05-60125 Арктика.

\section{Литература}

1. Денисов Д.Б., Кашулин Н.А. Цианопрокариоты озера Имандра (Кольский полуостров) // Цианопрокариоты (цианобактерии): систематика, экология, распространение Тезисы докладов Международной научной школы-конференции. 2016. С. 54-56.

2. Зубова Е.М., Кашулин Н.А., Терентьев П.М., Валькова С.А., Черепанов А.А., Постнова С.В. Новые данные по морфологическим особенностям жаберного аппарата мало- и среднетычинковой форм сига Coregonus lavaretus (L.) из крупнейшего субарктического озера // Биология внутренних вод. 2018. № 4. С. 63-74.

3. Методическое пособие по изучению питания и пищевых отношений рыб в естественных условиях. М.: Наука, 1974. 254 с.

4. Решетников Ю.С. Экология и систематика сиговых рыб. М.: Наука, 1980. 301 с.

5. Решетников Ю.С., Терещенко В.Г., Лукин А.А. Динамика рыбной части сообщества в изменяющихся условиях обитания (на примере оз. Имандра) // Рыб. хоз-во. 2011. № 6. С. 48-51.

6. Berezina N.A., Strelnikova A.P., Maximov A.A. The benthos as the basis of vendace, Coregonus albula, and perch, Perca fluviatilis, diets in an oligotrophic sub-Arctic lake // Polar Biology. 2018. № 41. P. 1789-1799.

7. Kashulin N.A., Dauvalter V.A., Denisov D.B., Valkova S.A., Vandysh O.I., Terentjev P.M., Kashulin A.N. Selected aspects of the current state of freshwater resources in the Murmansk region, Russia // Journal of Environmental Science and Health. Part A: Toxic/Hazardous Substances and Environmental Engineering. 2017. T. 52. № 9. C. 921-929.

8. Northcote T.G., Hammar J. Feeding ecology of Coregonus albula and Osmerus eperlanus in the limnetic waters of Lake Malaren, Sweden // Boreal Env. Res. 2006. № 11. P. 229-246. 